\title{
2
}

\section{INEQUALITY IN THE PUBLIC SPHERE}

\section{Epistemic injustice, discrimination, and violence}

\author{
Elisa Piras
}

\section{Introduction}

Contemporary democracies rely on the delicate balance between two fundamental principles of politics: as we can read at the beginning of almost every democratic constitution, within a democratic system all citizens are considered free and equal members of the political community. Even if we frame democratic politics in terms of fairness or social justice - setting the bar higher towards a normative definition of democracy, as a large number of contemporary political theorists do - the two principles at the heart of any conception of justice do not change, although their altemative interpretations can produce very different political outcomes. Within the public sphere, communicative interactions between individuals and groups occur daily, alternative opinions interact, and the public debate unfolds as the result of the exchange, influencing the democratic game, i.e. the formation of electoral majorities and the governments. Social and political inequalities affect the structure and functioning of the public sphere - the arena where public opinion emerges as the result of the continuous exchange of information and opinions. Within the public sphere, inequality produces harm and injustice for the members of marginalised groups. Drawing on the contemporary debate among liberal political theorists, the chapter will analyse the formation of public opinion, highlighting its political implications; then, it will explain and connect the concepts of epistemic and structural injustice; eventually, it will advance the concept of dialogic injustice to depict the specific form of epistemic injustice which harms members of marginalised and oppressed groups when they experience credibility deficits or apparently insurmountable difficulties in acceding to the public sphere as free and equal members.

\section{How inequalities affect the public sphere}

Liberty and equality, the two principles lying at the heart of liberalism and democracy, do very often meet and at times clash within the relational setting widely 
known as the public sphere: this is a domain of social life where public opinion is formed and where a sui generis social actor, the public, emerges (Habermas 1991: 398). ${ }^{1}$ Within the public sphere, information is spread/offered and obtained/ consumed. There, communication-based interactions between individuals and groups occur daily; alternative opinions are publicly stated, refuted, supported, and attacked. Moreover, since the public sphere is a filter between state and society, it is the domain of public reason (Rawls 1993; Habermas 1995; Gaus 2011; Forst 2014), where citizens' requests for justifications for state laws and actions arise and justificatory accounts are presented in response by the representatives of state institutions. Every citizen is entitled to ask and receive acceptable answers (reasonable justifications) when they question the ratio of political rules, because obedience to any authority is acceptable insofar as this serves the preservation or enhancement of citizens' liberty and equality (Gaus 1999; Forst 2014). The entitlement to justification can be derived also from the conception of the state as the result of a contract, or from the Kantian idea that all citizens are to be considered as co-legislators (Rawls 1999: 135-37). With respect to democracy, the public sphere is not only a filter, but also a fulcrum: allowing continuous communication between government and citizens, it guarantees the equilibrium, stability, and functioning of the system. There, political consensus can be built and eroded as part of the game for achieving political power; also, it is in the public sphere that the formation of electoral majorities occurs.

There are two main assumptions for the existence of a public sphere. First, within a certain society there is a sufficient degree of liberty to allow the proliferation of ideas, opinions, beliefs, and tastes. Second, all these different ideas, opinions, beliefs, and tastes can be publicly spelled out and any citizen has equal right to express her/his own thought or to profess her/his faith. Ideally, a democratic public sphere is characterised by reasonable pluralism: there is a wide variety of doctrines about truth or about what is good, but each of them respects the others and none aims at defeating all alternative doctrines (Rawls 1993: 38 ff.; Gaus 1999). Again, the two assumptions reflect the core principles of liberalism and democracy: liberty and equality. Within the public sphere, from the debate among free and equal citizens, not only the specific policies and laws, but also the constitutional principles of any democracy are periodically discussed and evaluated, making possible the participation of the public to the processes of constitutional reform which make democratic systems stable and resilient over time (Rawls 1993).

Several problems emerge when we shift from the ideal of the public sphere described above to the non-ideal conditions of existing democracies. In the next section, I will investigate how social and political inequalities affect the distribution of epistemic resources and how this unequal distribution negatively affects some individuals because of their belonging to marginalised groups, contributing to perpetuate their unjust marginalisation. However, another problem affecting the public sphere of existing democracies needs to be briefly mentioned here, since it is closely linked to that of epistemic injustice. Pluralism is not always reasonable: precisely because all doctrines and opinions can freely and equally circulate within the public sphere, also discriminatory and violent (non-reasonable) ideas can enter 
the public discussion. As a matter of fact, they often come together with abusive or insulting language and sometimes they can serve as triggers for actions of violence carried out by individuals or by organised groups. The problematic reconciliation between freedom of expression and equal respect with regard to what is often called hate speech or 'group libel' (Waldron 2012) is an especially thorny task, not only for political theorists, but also for politicians and for professionals working in the field of education as well as in the mass media system. Within liberal democracies, there is a trade-off between protecting freedom of expression for all citizens and combating discriminatory attitudes and discourses which are potentially harmful for marginalised minorities. There are at least two main solutions to this conundrum. The first solution is to set the boundaries to free speech and exclude from the public sphere any harmful speech which could undermine the dignity of the targeted people (ibid.). The second solution consists of evaluating on a case-by-case basis whether it is better to place a higher value on freedom of expression rather than on other liberal values (privacy, security, equality, or the prevention of harm), acknowledging the political nature of any limitation to free speech (Fish 1994).

The contemporary public sphere abounds of examples of discriminatory attitudes and discourses - among others, racism, xenophobia, anti-Semitism, antiGypsyism, ageism, sexism, homophobia, ableism, etc. - used to frame political narratives and build consensus for implicitly or explicitly discriminatory political projects. As Catharine MacKinnon explained, in similar cases "speech acts"; to put it differently, concern about the political implications of free speech is justified, since there is something hidden behind words: "In the context of social inequality, so-called speech can be an exercise of power which constructs the social reality in which people live, from objectification to genocide. (. . .) Social supremacy is made, inside and between people, through making meanings" (MacKinnon 1993: 31). Discriminatory discourses are powerful political resources, and they are especially easy to exploit within the contemporary public sphere, which is multimedia, fragmented, and rhizomatic. ${ }^{2}$ In this environment, pace to Kant (1784) and Habermas (1991), philosophers and public intellectuals are not the only ones who have the ability and authority to influence public opinion and participate in debates about politics. This is so because the public - the community of citizens where public opinion coalesces - is larger and much more composite compared to the past; consequently, both the language, the cultural references, and the messages used to build convincing argumentation have changed. Rationality, reasonableness, reciprocity, and civility, the pillars of the most influential liberal accounts of the public sphere elaborated during the last two centuries and a half, seem to give way to new features of public discourse that we can easily spot in contemporary political debates: unrestrained appeal to emotions, spontaneity, simplicity, refusal of the politically correct (Salmon 2013).

At this point, one might ask: why is it so important how public opinion is formed? It is because in a democracy public opinion grounds political consensus for the actors who can acquire political power. While observing the democratic 
'market of opinions', it is paramount to detect which opinions look more appealing to the public, to trace the actors who back up those opinions and to identify the social mechanisms favouring their diffusion. ${ }^{3}$ Since they have a crucial role for the formation of individual opinions and then of public opinion and consensus, information and communication deserve special attention. This comes as no news: almost a century ago, John Dewey (1927) convincingly raised this point while he was looking for an answer to the question: why is the US, notwithstanding the military and economic achievements which made its society great, a soulless and defective democracy? The answer is that the institutional mechanisms are not enough if the sense of community is missing. An ideal public sphere would present a fair market of opinions, based on reliable information provided by independent professionals sincerely committed to offer neutral accounts of the facts. Within such a public sphere, there would be an ideal public, capable of distinguishing the quality of the information, to collect it from different sources and to assess it thanks to critical reasoning. Public opinion emerging from the interactions among individual opinions would then support the best political option available, and possibly concur to its definition. Thus, in front of this public, there would be a government sustained by a (well-deserved) consensus, representing the interests of the society, pursuing the common good and reasonably justifying its actions. Both the conditions of reasonable pluralism and public reason would be realised (Rawls 1993). Like contemporary proponents of deliberative and participatory accounts of democracy, Dewey assigned a central importance to discussion, consultation, persuasion, and debate for democratic decision-making; of course, in his theoretical account high-quality education and unbiased information available for all citizens are fundamental prerequisites for the life of a democratic community.

Unfortunately, in non-ideal circumstances unequal access to good education and biased information are two of the reasons why the public sphere is not equally accessible to all the citizens, while it is especially hospitable to the powerful actors who can mobilise resources and know-how to influence public opinion. They do so by producing and spreading biased information and disseminating opinions and narratives which are suitable to further their interests, either to achieve or preserve political power or to maintain the social status quo. The new communication media, especially the Internet and the social networks, are very useful in this respect, since they allow the replacement of rational discourses with emotional messages, selecting the information sources and opinions that each citizen is exposed to on the basis of her/his status within society and of her/his social connections. An effect of this would be the transformation of our democracies towards a model of bubble democracy: the public dissolves into a myriad of self-referential 'bubbles', each allowing its 'inhabitants' to hear and read only the information and opinions which match their pre-established personal opinion. Thus, the public sphere is more and more fragmented and polarised, and the epistemic fruitfulness of the debate within the bubble is nullified: the ideas circulating within each bubble are homogeneous and they do not change 
over time (Palano 2020). This explains also why in contemporary democratic societies a vast majority of the citizens are unable to collect information, formulate their own interests, and mobilise; thus, they are governed by a restricted elite who is able to perform this tasks effectively (Goodin and Spiekermann 2015). The first move for marginalised and oppressed groups to take an active part in the public debate could be to develop epistemic solidarity, the "strategy of pooling information with selected others" (ibid.: 440). This would help citizens to bypass two paradoxical problems of the insufficient exposure to alternative opinions which characterise contemporary communication: epistemic bubbles - the condition of citizens who are limited in their attempts to formulate their own opinions because they have access to a small number of opinions, and echo chambers - the condition where some opinions are actively excluded and discredited (Sunstein 2009; Nguyen 2018). To simplify, "epistemic bubbles exclude through omission, while echo chambers exclude by manipulating trust and credence" (Nguyen 2018: 2). The same social epistemic phenomena facilitate the dissemination of fake news, post-truth messages, false or misleading political narratives. ${ }^{4}$ These are especially worrisome features of the contemporary public sphere, not only because they hamper the discussion about the common good, but also because in order to do so they tend to exploit and exacerbate existing social inequalities, setting some groups against other groups and reproducing marginalisation and oppression.

\section{Two effects of discrimination: Epistemic and structural injustice}

In the previous paragraph, some concepts of social epistemology have been taken into consideration. Social epistemology is a subdiscipline of epistemology which examines and critically evaluates "the processes through which beliefs, decisions and opinions are formed, maintained and revised by individuals, groups, institutions and, in the widest sense, social practices and social systems" (Prijić-Samaržija 2018: 21). Similar investigations are particularly interesting for political philosophers: in 1690, at the outset of liberal thought, John Locke formulated the 'law of opinion or reputation'. 5 This explains how, by approving or disapproving of an individual's ideas and actions, other people exert a pressure on her/him to conform to a certain way of thinking and behaving which is acceptable or mainstream in her/his social environment. Humans are social animals; they fear isolation and peers' reprobation. Therefore, the majority of individuals will express their opinion in public only if they do not risk appearing as social outcast - this, of course, does not mean that divergent opinions cease to exist; they are hidden and in some cases they can resurface. In democratic contexts, we could observe the sudden appearance of hidden political opinions in numerous elections which showed unpredicted results people use their quasi-statistical sense to understand the prevailing opinion in their social environment and, in case they have a different opinion, they tend to conceal it: this is the so-called spiral of silence theory (Noelle-Neumann 1980). 
There are two insights in Locke's reflection on the problem of individual opinions which are relevant for the present discussion: first, the coercive nature of society over the individual; second, the importance of personal reputation and esteem for any citizen who hopes to be integrated. ${ }^{6}$ If we consider them carefully, we can see that, again, there are two principles at stake: liberty and equality.

A serious threat to the principle of equality is connected to the importance of reputation and esteem: because of individuals belonging to certain groups, they may experience epistemic harm as a result of a negative identity-based prejudice. Epistemic injustice, as it has been defined in an influential essay written by Miranda Fricker (2007), is a form of injustice which may assume two forms: testimonial injustice and hermeneutical injustice. Testimonial injustice means that a person's testimony is not considered reliable or is not taken seriously because of her/his identity, which is read in the light of prejudices and stereotypes that undermine her/his credibility. On the other hand, hermeneutic injustice applies when a person suffers injustice but is not fully aware of it - because of the cultural context in which one is marginalised - and therefore fails to recognise and denounce the injustice. To clarify these two concepts, it is helpful to consider two examples, both taken from the 2011 movie The Help, directed by Tate Taylor. The film is set in the US in 1963. One of the African-American service women protagonists, Aibileen Clark, is falsely accused of stealing three silver pieces of cutlery from the house where she works. Although Aibileen tries to prove her honesty by providing a (true and) plausible narrative of what happened, her testimony is not believed and the (white) landlady fires her. In this case, we can talk about witness injustice. Minny Jackson, another African-American maid, is a victim of continuous violence by her husband but has no clear perception of the injustice she is a victim of and the crime that is repeatedly committed by her husband against her, and so fails to improve her condition. She cannot put into words the injustice that she experiences; therefore, she does not consider herself as a victim. This second case falls into the category of hermeneutical injustice. ${ }^{7}$

Epistemic injustice is closely connected with structural injustice, a phenomenon which has been investigated by feminist and postcolonial scholars (Young 1990; Lu 2018). This particular kind of injustice pertains to the whole socio-political system:

A social structure can be said to be unjust when the rules perpetuated through it persistently disadvantage some social groups vis-à-vis others. Whatever baseline is chosen to help identify structural injustice, if the injustice is to count as structural and not merely a result of unfair or unequal distribution, it must express some more persistent or deeper power-differential between social groups

(Jugov and Ypi 2019).

Both forms of injustice are linked to the existence of a structural asymmetry of epistemic power: in society, some people have identities that give them an advantage 
in cases where credibility comes into play, while others are (consciously or unconsciously) considered as lacking in credibility by a large number of people. In processes where conflicting narratives about a given event are weighed up, epistemic injustice can play a crucial role in the fate of the victim and the accused, and the dynamics of the economy of credibility can be more relevant than the determination of factual truth.

Although Fricker focuses on the trial phase, it should be noticed that epistemic injustice can also have a significant impact in the investigative phase, in media coverage and in public reception of news about a certain criminal event. In other words, in the judgement, rather than an objective evaluation of epistemic credibility, which can be established if there is competence and sincerity in a testimony, an evaluation vitiated by the existence of negative identity-prejudicial stereotypes related to the identity of the witness prevails. This is an implicit epistemic distortion (bias) which may be potentially harmful for the members of marginalised groups and for the groups as such, because instances of "persistent and systematic" epistemic injustice reinforce and perpetuate the systemic marginalisation and discrimination of the whole group (ibid.: 28).

Generalising from the case of testimonial injustice, we could say that in the process of formation of public opinion the members of marginalised groups experience dialogic injustice, that means that they are not considered as equal partners in the exchange of information or opinions which lead to the construction of public opinion. They lack the reputation and credibility - and very often the self-esteem needed to actively take part in discussions concerning the political good. Because of hermeneutical injustice, very often a person who is unjustly marginalised in the public sphere fails to recognise it as an injustice and therefore is unable to react to the injustice. In a similar situation, the person is not 'epistemically aware', but her/ his capacity of analysing reality and of acting toward its transformation is reduced because of partial or total 'epistemic opacity' (ibid.: 14-17). Overcoming dialogic injustice is especially challenging, since the contemporary public sphere presents significant obstacles to the participation of members of discriminated and marginalised groups on conditions of equality. In addition to the perceived credibility deficit and the self-censorship that this might bring about, the technological tools and skills needed to access the public sphere on a regular basis, the considerable time needed to acquire reliable information, the difficulty in identifying trustworthy epistemic authorities and the diffusion of discriminatory discourses and narratives, combined with the unbridled resort to hate speech, are some of the challenges ahead. Perhaps the first action needed in order to start a transformative process for changing the public sphere and making it more in line with the principles of liberty and equality is to organise collective action and activate epistemic solidarity in order to influence the formation of public opinion.

\section{Conclusion}

Looking at the socio-political implications of epistemic injustice, it is important to notice how it is linked to the unequal distribution of power within the society 
and how it harms the lives of the marginalised members, not only during police investigation or trials, but in how it reproduces and strengthens their condition of marginalisation and oppression. In particular, this chapter showed that credibility deficits due to negative-identity stereotypes affect members of marginalised groups even when they take part in any public discussion or when they abstain from participating because they think their opinion would not be heard. In analogy with the epistemic injustice, this phenomenon could be called dialogic injustice. The persistent and systematic credibility deficit, together with the lack of time, technological devices and skills, explains why often members of the marginalised groups tend not to enter the public sphere or, when they do so, they do not participate on an equal foot - as Fricker notes, identity power "at once constructs and distorts who the subject really is," conditioning her/his own understanding of the self (Fricker 2007: 55).

It is important to point out that the absence or silence of marginalised people within the public sphere has a negative impact not only for their individual lives, but also for the formation of public opinion - which, as seen in the first section of the chapter, matters when it comes to supporting candidates for government positions. Public opinion emerges from the exchange of views about politically relevant issues; if the number of opinions is reduced, the diagnosis of the relevant problems and the search for viable solutions will be based on partial evidence and reflect the interests of a part of the society.

\section{Notes}

1 In the final part of his seminal work, Habermas maintains that the public sphere as he defines it has been functioning for a relatively short period in history - from the rise of the bourgeoisie during the 18 th century to its crisis, which emerged by the half of the 20 th century - and that it would have entered a situation of crisis with the advent of globalised capitalism and the simultaneous processes of depoliticisation/cooptation of labour, culture, and education. According to Habermas, public opinion would be more and more politically irrelevant or prey of the manipulations of the powerful actors of the market. Nonetheless, the concept of the public sphere - analysed, criticised, and reassessed - from many perspectives is still widely used by sociologists as well as by political philosophers not only for reflecting about the past, but also about the present (cfr. Fraser 1990; Calhoun 1992; Benhabib 1997; Palano 2020). For a critical reappraisal of the significance of Habermas' contribution for the debate, see Genscher (2006).

2 For a brief reconstruction of the main features of the debate on the conceptualisation of the public sphere for the digital era, see Casadei (2014).

3 As Antonio Gramsci (2014) pointed out, looking at the experience of the coming to power of the Fascist party in Italy during the 1920 s, the progressive construction of political consensus requires the widespread dissemination within the public sphere of ideas and ideals (elements which combine to form a worldview, or a comprehensive political doctrine). The final goal is to acquire cultural hegemony and maximise consensus, eventually obtaining political power. Disseminating anti-democratic ideas, which implicitly undermined the principles of liberty and equality, Mussolini and his party won the democratic game and made loot of democratic institutions and laws.

4 A stimulating discussion on the evolving relationship between truth and politics emerges from the different political philosophers' contributions presented in Bistagnino and Fumagalli (2019). In particular, Antonella Besussi, Paolo Gerbaudo, and Valeria Ottonelli look from different angles at one main question that is crucial for the discussion presented 
in this book: the change of the truth-authority nexus that is occurring within democratic societies. On the same topic, see also Stuart Sim's discussion of the emergence of post-truth politics and the ambiguous transformation of liberal societies towards a post-liberal condition which might entail progressive or conservative developments (Sim 2019: 139-53). Among the many recent reflections focussing especially on how post-truth affects contemporary philosophical thinking about politics, see Palano (2020) and Newman (2019).

5 The problem of peer pressure and of the effects of conformism produced by the society has been explored more in-depth in 1859 by John Stuart Mill, who looked at its effects both on the cultural and political domain. In the latter, the concept of the law of opinion was translated into that of the tyranny of the majority, in which a democratic majority forces its will on the minority. For a reading of the history of political thought from the perspective of a theory of public opinion, see Noelle-Neumann (1980).

6 Locke presents another thought-provoking idea: the diffusion of certain opinions is (also) a matter of fashion. This means that widely held opinions are more likely to be publicly stated than extravagant opinions. Moreover, as happens with any fashion, there is at least one trend-setter, who, consciously or unconsciously, triggers the diffusion of a certain opinion.

7 In both cases, the discrimination is intersectional: both Aibileen and Minny are victims of discrimination for at least three reasons: because they are African American, because they are women, because they belong to the working class. For a discussion on how intersectionality works for epistemic injustice, see Hill Collins (2017). See Medina (2017) for a discussion of the different forms of hermeneutical injustice.

\section{References}

Benhabib, S. (1997) 'The embattled public sphere: Hannah Arendt, Jürgen Habermas and beyond', Theoria 44: 1-24.

Bistagnino, G., C. Fumagalli (eds) (2019) Fake news, post-verità e politica, Fondazione Feltrinelli ebook.

Calhoun, C. (1992) 'Introduction: Habermas and the public sphere', in: Id. (ed.), Habermas and the Public Sphere, Cambridge, MA - London: MIT Press, 1-50.

Casadei, T. (2014) 'La democrazia nell'era di Internet: la filosofia politica di Pierre Lévy e il dibattito contemporaneo sulle reti digitali', Filosofia Politica XXVIII(1): 143-54.

Dewey, J. (1927) The Public and Its Problems, New York: Holt.

Fraser, N. (1990), 'Rethinking the public sphere: A contribution to the critique of actually existing democracy', Social Text 25-6: 56-80.

Fish, S. (1994) There's No Such Thing as Free Speech . . and It's a Good Thing Too, New York: Oxford University Press.

Forst, R. (2014) Justification and Critique: Towards a Critical Theory of Politics, Cambridge: Polity Press.

Fricker, M. (2007) Epistemic Injustice: Power and the Ethics of Knowing, Oxford: Oxford University Press.

Gaus, G. (1999) 'Reasonable pluralism and the domain of the political: How the weaknesses of John Rawls's political liberalism can be overcome by a justificatory liberalism', Inquiry. An Interdisciplinary Joumal of Philosophy 42(2): 259-84.

Gaus, G. (2011) The Order of Public Reason: A Theory of Freedom and Morality in a Diverse and Bounded World, Cambridge: Cambridge University Press.

Gestrich, A. (2006), 'The public sphere and the Habermas debate', German History 24(3): 413-30.

Goodin, R.E, K. Spiekermann (2015) 'Epistemic solidarity as a political strategy', Episteme 12(4): 439-57. 
Gramsci, A. (2014) Quademi dal Carcere, edizione critica dell'Istituto Gramsci a cura di Valentino Gerratana, Torino: Einaudi.

Habermas, J. (1991) (or. ed. 1962) The Structural Transformation of the Public Sphere: An Inquiry into a Category of Bourgeois Society, Cambridge, MA: MIT Press.

Habermas, J. (1995) 'Reconciliation through the public use of reason: Remarks on John Rawls's political liberalism', The Joumal of Philosophy 92(3): 109-31.

Hill Collins, P. (2017) 'Intersectionality and epistemic injustice', in: J. Kidd, J. Medina, G. Pohlhaus (eds), The Routledge Handbook of Epistemic Injustice, Abingdon - New York: Routledge, $115-24$.

Jugov, T., L. Ypi (2019) 'Structural injustice, Epistemic opacity, and the responsibilities of the Oppressed', Journal of Social Philosophy 50(1): 7-27.

Kant, I. (1784) 'An answer to the question: What is enlightenment?', in Id. (1996), Practical Philosophy translated and edited by M.J. Gregor, Cambridge - New York: Cambridge University Press.

Locke, J. (1690) Essay Conceming Human Understanding, Book II, chapter 28, 7-13.

Lu, C. (2018) 'Responsibility, structural injustice, and structural transformation', Ethics $G$ Global Politics 11(1): 42-57.

MacKinnon, C. (1993) Only Words, Cambridge, MA: Harvard University Press.

Medina, J. (2017) 'Varieties of hermeneutical injustice', in: J. Kidd, J. Medina, G. Pohlhaus (eds), The Routledge Handbook of Epistemic Injustice, Abingdon - New York: Routledge, $115-24$.

Newman, S. (2019) 'Post-truth and the crisis of the political', Soft Power 6(2): 91-108.

Nguyen, C.T. (2018) 'Echo chambers and epistemic bubbles', Episteme, https://doi. org/10.1017/epi.2018.32

Noelle-Neumann, E. (1980) (or. ed. 1974) The Spiral of Sitence: Public Opinion - Our Social Skin, Chicago: University of Chicago Press.

Palano, D. (2020) La fine del pubblico e la nuova polarizzazione, Brescia: Scholé.

Prijić-Samaržija, S. (2018) Democracy and Truth. The Conflict Between Political and Epistemic Virtues, Udine: Mimesis.

Rawls, J. (1993) Political Liberalism, New York: Columbia University Press.

Rawls, J. (1999) 'The idea of public reason revisited', in Id., The Law of Peoples, Cambridge, MA: Harvard University Press.

Salmon, C. (2013) La cérémonie cannibale: De la performance politique, Paris: Librairie Arthème Fayard.

Sim, S. (2019) Post-Truth, Scepticism \& Power, Cham: Palgrave Macmillan.

Sunstein, C.R. (2009) Going to Extremes: How Like Minds Unite and Divide, Oxford: Oxford University Press.

Waldron, J. (2012) The Harm in Hate Speech, Cambridge, MA - London: Harvard University Press.

Young I.M. (1990) Justice and the Politics of Difference, Princeton: Princeton University Press. 